\title{
Food consumption habits of consumers in the Philippines: Changes amidst the pandemic
}

\author{
Jonathan N. Tariga ${ }^{1}$, Dyanika P. Nolasco ${ }^{2}$, Syrille Joyce R. Barayuga ${ }^{3}$ \\ ${ }^{1}$ College of Hospitality Industry Management, Quirino State University, Diffun, Quirino, Philippines \\ ${ }^{2}$ Research and Development Office, Quirino State University, Diffun, Quirino, Philippines \\ ${ }^{3}$ College of Information Technology and Computing Sciences, Quirino State University, Diffun, Quirino, Philippines
}

\begin{tabular}{l} 
Article Info \\
\hline Article history: \\
Received Jan 14, 2021 \\
Revised May 23, 2021 \\
Accepted Jun 18, 2021 \\
\hline
\end{tabular}

\section{Keywords:}

Consumers

Eating patterns

Food choices

Food consumption habits

Pandemic

\begin{abstract}
A quantitative descriptive strategy was applied to identify food patterns for Filipino consumers before, during and after the COVID-19 pandemic. Sampling was carried out using simple random sampling techniques. An electronic-questionnaire served as primary research instrument and was distributed through social media platforms to which 80 out of 250 responses were selected. Simple quantitative analysis such as mean value, frequency distribution and percentage were utilized. Results showed that the most of the respondent's diet has wellness, social and psychological influence. Organic diet desires and self-cooking practices are continuing to grow. The study also showed that the essential aspects of food choice, health, quality and safety are increasingly being taken into account. The COVID-19 pandemic shifted the habits of food intake to healthier, influencing even the preference of consumed food. Thus, this study can be used as a theoretical guide especially for factors influencing the eating patterns during a pandemic. Ergo, food establishments can make use of the results to strategize to combat the COVID-19 pandemic by improving product quality on the basis of consumer needs and demands.
\end{abstract}

This is an open access article under the CC BY-SA license.

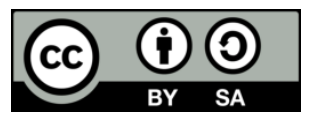

\section{Corresponding Author:}

Jonathan N. Tariga

College of Hospitality Industry Management

Quirino State University

Andres Bonifacio, Diffun, Quirino, 3401, Philippines

Email: jonathan.tariga@qsu.edu.ph

\section{INTRODUCTION}

The coronavirus disease (COVID-19) caused the world trouble and uncertainties. Because of its rapid widespread, it was tagged extremely infectious as it caused severe respiratory infection that might lead to death [1], [2]. As such, COVID 19 pandemic also affected the spending patterns of consumers entire the globe. The lockdown initiatives had a massive influence on daily life, frequently with adverse impact on mental well-being [3]. Food preferences have obviously changed. Tourism has negatively been affected specifically restaurant operations. People have started to focus on food health issues. They become more specific about the food quality they consume on a daily basis [1], [4]. With all these concerns, people need to maintain immunity against the disease. Thus, consumers were directed to follow health protocols to reduce the transmission of COVID 19. WHO also urged people to live a healthy lifestyle by consuming healthier foods and reducing or avoiding alcohol [5].

Many researches have shown how many people do seem to have a variety of psychological consequences and challenges to adapt to the new lifestyle of quarantine [6]. Women suffer more than men. 
Furthermore, less educated individuals, children and teens reported high levels of stress, anxiety, mental health problems and psychological impact [7]. Food is crucial to a culture and world heritage. With this, perception of individuals on food is different for each community. Manifestation and symbolisms of food are also diverse, both on food itself and how it is consumed. Food consumption activities are based on Maslow's hierarchy of needs [5]. The hierarchy of needs connects to the economic cycle which shows how consumers adjust their consumption behavior during a crisis so they can prioritize spending on their essential needs. In addition, the need to meet self-esteem and self-actualization, food choices and personalities is also changed. To satisfy this, people often try new foods and recipes without following selection patterns. Different factors affect the habit of eating.

Though people have the urge to meet needs even this time of pandemic, this situation comprises one's maintenance of a healthy and good diet. This could be brought about by limited access to daily grocery shopping or market buying which could lead to reduced consumption of fresh foods and higher intake of convenient, unhealthy foods [8]. However, at this time of crisis, being healthy is a must. Since inadequate nutrition can cause micronutrient deficiencies and chronic diseases which may lead in a rise in medical expenses, a reduction in work capacity and ultimately, economical detriments. Thus, appropriate nutrition plays an essential part to improve health $\mathrm{s}$ and increase body immunity against diseases. When one takes adequate nutrients and energy, the development of some diseases and nutritional disorders can be prevented.

Several factors affect the consumption habits of an individual, especially those related to food. Preferences and interests are not only affected individually, but also influenced socially [9]. In today's culture, eating-healthy may seem at first glance a very routine and invisible human activity. However the recognition of health-care food as an ethical activity of self-formation helps us to see "food" as a field where "self" and "social" resonate together [10].

Food preferences are highly complex, personal, and influenced by a broad variety of factors, especially physiological [11]. According to Vallejo [12], food preferences or choices discuss how people choose the food they consume. It includes psychological, sociological, economic, sensory and other aspects. The food choice is driven by taste preferences, sensory characteristics, prices, availability, comfort, cognitive restraint, and cultural familiarity. The pandemic influenced people in preparing their own food with the guidance of "online chefs." Their eating patterns were also affected.

Thus, this phenomenon is an interesting area to venture on especially that public consumption patterns has changed during the pandemic. This study is therefore intended to identify consumer food consumption habits before, during and after the pandemic in the Philippines. It focuses on offering possible measures immediately after the end of the pandemic. This research can be used as a theoretical guide especially for factors influencing the eating patterns during a pandemic. Ergo, food establishments will use the results of this research to create strategies for survival during time of crises such as this to improve product quality on the basis of consumer needs and demands.

\section{RESEARCH METHOD}

This study adopted a descriptive survey design to describe consumer consumption in the Philippines before, during, and after the pandemic in the Philippines. It used probability sampling technique through simple random sampling to identify the respondents. Data collection was carried out from July-September 2020 using an online survey questionnaire which was distributed through online platforms. It involved 80 respondents of various sexes, ages, educational and professional backgrounds, marital status, number children and monthly household income. Questions were adapted from the study of Chakraborty et al. [13] which was developed on the present condition considering various theories that influence consumer behavior to include social, cultural and psychological factors [4], [14], [15]. The instrument used multiple-choice answer choices which explored the agreement of respondents on several questions pertaining their food consumption patterns. Responses were analyzed through appropriate statistical tools to frequency, percentage, and mean value.

\section{RESULTS AND DISCUSSION}

\subsection{Respondent's profile}

Results show that majority of the respondents were female and belongs to generation $\mathrm{Y}$ which implies a greater interest for female to involve themselves in surveys like this and fill-up questionnaires pertaining to food consumption patterns. This is most likely due to the fact that women are the primary decision-makers when it comes to food selection. As to age, a large portion has ages 21-30 years, followed by 31-40, and 41-50 years. Those that belong to Generation Y were born between 1980-1994 and were referred to as first technology and global generation of the world. They are called millennials or the digital generation. They are significantly known for being the highly educated generation since they are grown in a 
technology age. They are into speedy changes and responds flexibly to them [16]. Mostly, respondents obtained their bachelor's degree and were into functionary. More than half of them were married but about 44\% do not have children. Most of them belong to lower level with a monthly income of less than 19,040. Respondents demographics a shown in Table 1.

Table 1. Respondents demographics

\begin{tabular}{|c|c|c|c|}
\hline Profiles & Choices & Frequency & Percentage (\%) \\
\hline \multirow{2}{*}{ Gender } & male & 27 & 34 \\
\hline & female & 53 & 66 \\
\hline \multirow{5}{*}{ Age } & $17-20$ years old & 3 & 4 \\
\hline & 21-30 years old & 41 & 51 \\
\hline & $31-40$ years old & 18 & 23 \\
\hline & $41-50$ years old & 13 & 16 \\
\hline & $>50$ years old & 5 & 6 \\
\hline \multirow{4}{*}{$\begin{array}{l}\text { Educational } \\
\text { background }\end{array}$} & high school equivalent & 8 & 10 \\
\hline & bachelor's degrees & 40 & 50 \\
\hline & postgraduate & 33 & 41 \\
\hline & students & 11 & 14 \\
\hline \multirow{4}{*}{$\begin{array}{l}\text { Professional } \\
\text { background }\end{array}$} & private employees & 6 & 8 \\
\hline & functionary & 36 & 45 \\
\hline & entrepreneurs & 4 & 5 \\
\hline & others & 23 & 29 \\
\hline \multirow{2}{*}{ Marital status } & single & 35 & 44 \\
\hline & married & 45 & 56 \\
\hline Number & 0 & 35 & 44 \\
\hline of children & $1-2$ & 36 & 45 \\
\hline \multirow[t]{2}{*}{ (if applicable) } & $>2$ & 9 & 11 \\
\hline & $\begin{array}{c}\text { between PHP } 9,520 \\
\text { to PHP } 19,040\end{array}$ & 34 & 43 \\
\hline \multirow[t]{2}{*}{ Monthly household income } & $\begin{array}{c}\text { between PHP } 19,040 \\
\text { to PHP } 38,080\end{array}$ & 24 & 30 \\
\hline & > PHP 38,080 & 22 & 27 \\
\hline
\end{tabular}

\subsection{Food consumption habit}

Changes in consumption habits were grouped into three types: pre-pandemic, during-pandemic, and post-pandemic. This period was chosen to end and offer opportunities related to changes in people's patterns of consumption, especially food habits.

\subsubsection{Before the pandemic}

COVID-19 made its global debut in Wuhan, China, in December 2019. On the second week of March 2020, The Philippine government has announced lockdowns in Metro Manila, followed by the entire Luzon Island and is mulling over more localized lockdowns. The Philippines government declared a state of calamity in the country for six months in March 17. Before the pandemic, where the human movement was not restricted and were to access services, Filipinos had developed a habit of dining outside residence. Most of the consumers who participated in the survey (41\%) specified that they do dining outside once a month, $38 \%$ weekly, $15 \%$ twice a week, and $5 \%$ daily. The vast majority of respondents stated that they cooked at home on a daily basis. Concurrently, $6 \%$ of respondents did it twice a week, $1 \%$ once a week. Ergo, prior to the pandemic, the most common types of food purchased were non-organic (53\%) and organic (47\%). Table 2 shows the consumption habits of pre-pandemic respondents. This implies that before the pandemic, people often dine out in a month but cook food daily at home and prefer more non-organic foods.

Table 2. Prepandemic food eating habit

\begin{tabular}{ccc}
\hline Survey issues & Choices & Percentage (\%) \\
\hline & Daily & 5 \\
Before the pandemic, how often did you eat out? & Twice a week & 15 \\
& Weekly & 39 \\
How often did you cook your own food before the pandemic? & Monthly & 41 \\
& Twice a week & 93 \\
What is your food preference before the pandemic? & Weekly & 6 \\
& Monthly & 0 \\
& Organic & 47 \\
\hline
\end{tabular}

Int. J. Public Health Sci., Vol. 10, No. 3, September 2021 : $662-669$ 


\subsubsection{During pandemic}

During the pandemic, activities outside the home are limited, including dining. In the Philippines, food establishments and malls except supermarkets are closed based on the recommendation of the Philippine Inter Agenecy Task Force. As a result, researchers observed deviations in consumption habits during the pandemic. Based on the survey results, during the pandemic, most of those who participated in the survey 98\% cooked their food every day. Respondents' preference for food purchase is organic with $78 \%$ while the rest preferred non-organic foods. They prefer to consume fresh meat, vegies, and fish (98\%), processed food (39\%), and made to order noodle food delivery (20\%), fast food deliveries (18\%), Diningout (10\%), and other combination (1\%). Fresh raw materials such as veggies, fruits, meats, are the most commonly purchased foods during a pandemic, accounting for $84 \%$ of total purchases. Likewise, with groceries (34\%), breads and pastries with $28 \%$, ready-to-eat products with $24 \%$, and frozen meals (20\%). Meanwhile, the table reveals that changes in food preference tends to be healthier with $48 \%$ of the respondents agreed followed by $29 \%$ strongly agree. Table 3 displays the eating patterns of respondents during the pandemic.

Since, people were restricted to stay home to prevent local transmission; they prefer to cook at home daily. Results also imply that people tend to make healthier food choices during the pandemic as they prefer organic and fresh foods. They also perceive that aside from them, mostly people purchase fresh raw materials like fruits, veggies and meat. With this, they agreed that their food consumption habit changed during the pandemic.

Table 3. During pandemic food eating habit

\begin{tabular}{|c|c|c|}
\hline Suvey issues & Choices & $\begin{array}{l}\text { Percentage } \\
(\%)\end{array}$ \\
\hline \multirow{4}{*}{$\begin{array}{l}\text { During the COVID-19 Pandemic, how often do you cook your } \\
\text { food? }\end{array}$} & Daily & 98 \\
\hline & Twice a week & 2 \\
\hline & Weekly & - \\
\hline & Monthly & - \\
\hline \multirow{2}{*}{ What are your food preferences during COVID-19? } & Organic & 78 \\
\hline & Non-Organic & 22 \\
\hline \multirow{6}{*}{ What are the types of food you purchase? } & Fresh food (meat, veggies, fish.) & 98 \\
\hline & $\begin{array}{l}\text { Fast food delivery (Burgers, fries, broasted chicken, } \\
\text { petit fours.) }\end{array}$ & 18 \\
\hline & $\begin{array}{l}\text { Made-to-order Noodles (Lomi, Pancit Cabagan, } \\
\text { pansit batil patung.) }\end{array}$ & 20 \\
\hline & Processed Frozen Food & 39 \\
\hline & Dining-eating Out & 10 \\
\hline & Others (combination) & 1 \\
\hline \multirow{9}{*}{ What are the types of food most procured during pandemic? } & Fresh raw food (veggies, fruits, meats.) & 84 \\
\hline & Groceries (rice, sugar, salt, cooking oil.) & 34 \\
\hline & $\begin{array}{l}\text { Ready to eat products (instant noodles, oatmeals, } \\
\text { instant rice.) }\end{array}$ & 24 \\
\hline & Frozen meals (hotdogs, longganisa, tocino) & 20 \\
\hline & Dairy Products and Milk & 16 \\
\hline & Energy Drinks & 11 \\
\hline & Breads and Pastries & 28 \\
\hline & Junk Foods (candy, cheese curls) & 5 \\
\hline & Canned goods (sardines, meatloafs, and century tuna) & 26 \\
\hline \multirow{5}{*}{$\begin{array}{l}\text { Does the COVID- } 19 \text { pandemic influence your dietary } \\
\text { preferences to be healthier? }\end{array}$} & Strongly agree & 29 \\
\hline & Agree & 48 \\
\hline & Quite agree & 19 \\
\hline & Disagree & 4 \\
\hline & Strongly disagree & - \\
\hline
\end{tabular}

\subsubsection{Post-pandemic}

The consumption habit of the post-pandemic respondent will likely remain healthy. Most of the respondents who participated in the survey strongly agreed to continue cooking their own food, 53\% were undecided if they dine-out if the pandamic is over and done. $40 \%$ responded to eat outside their residences if the pandemic is ended in less three months. Respondents found three significant factors when dining out: the taste $(38 \%)$, the sanitary practices of the establishment $(35 \%)$, and the health benefits and novelty with both (23\%). Preferred food after COVID-19 is organic. Predictions of the consumption habit of respondents in post-pandemic can be seen in Table 4. 
Table 4. Post-pandemic possibility of food consumption behavior

\begin{tabular}{|c|c|c|}
\hline Questions & Options & $\begin{array}{l}\text { Percentage } \\
(\%)\end{array}$ \\
\hline \multirow{5}{*}{ I will continue my healthier choice of food after this pandemic has passed } & Strongly agree & 46 \\
\hline & Agree & 43 \\
\hline & Quite agree & 10 \\
\hline & Disagree & 1 \\
\hline & Strongly disagree & 1 \\
\hline \multirow{3}{*}{ I will return dining-out right after this pandemic is over. } & Yes & 40 \\
\hline & No & 9 \\
\hline & Maybe & 53 \\
\hline \multirow{3}{*}{ How long after this pandemic has ended do you intend to dine-out? } & Less than 3 months & 41 \\
\hline & 4-6 month & 28 \\
\hline & $>6$ months & 31 \\
\hline \multirow{5}{*}{$\begin{array}{l}\text { What are the factors that you will choose to consider in dining out after the COVID } \\
19 \text { ? }\end{array}$} & Taste & 38 \\
\hline & Foods novelty & 23 \\
\hline & Its health benefits & 23 \\
\hline & $\begin{array}{l}\text { Sanitary practices of the } \\
\text { place }\end{array}$ & 35 \\
\hline & Services & 10 \\
\hline \multirow{5}{*}{ I will intend to cook my own food after this pandemic is over } & Strongly agree & 54 \\
\hline & Agree & 46 \\
\hline & Quiet agree & 3 \\
\hline & Disagree & - \\
\hline & Strongly disagree & 4 \\
\hline \multirow{2}{*}{ Preferred food after COVID19 } & Organic & 81 \\
\hline & Non-organic & 19 \\
\hline
\end{tabular}

\subsection{COVID-19 pandemic effect on food consumption habit}

A series of studies and surveys worldwide indicate that COVID-19 lockdown has influenced the psychological well-being of the population [17]-[19]. Some of the study's results are linked to shifts in people's eating habits following the COVID-19 pandemic, such as an increase in the pattern of cooking at home, an increase in the intention of consuming organic food, an increase in food health knowledge, and an increase in the value of food quality and protection [1]. Ergo, customers spending habit is influenced by demographic, social, cultural and psychological factors [1], [15]. Consumers search for products, which have images compatible to their perceptions of self [20].

\subsubsection{The rising trend of homebased gastronomy}

Figure 1 depicts a growing pattern of homebased cooking both before and after the pandemic. According to the results, respondents who cook every day have a 5\% rise, while those who do not cook frequently decrease. Ergo, home cooking behavior can be influenced by a myriad of individual, interpersonal, and environmental factors which include but are not limited to food and cooking skills, values and enjoyment of cooking, education and nutrition knowledge, culture and ethnicity, and resources [21].

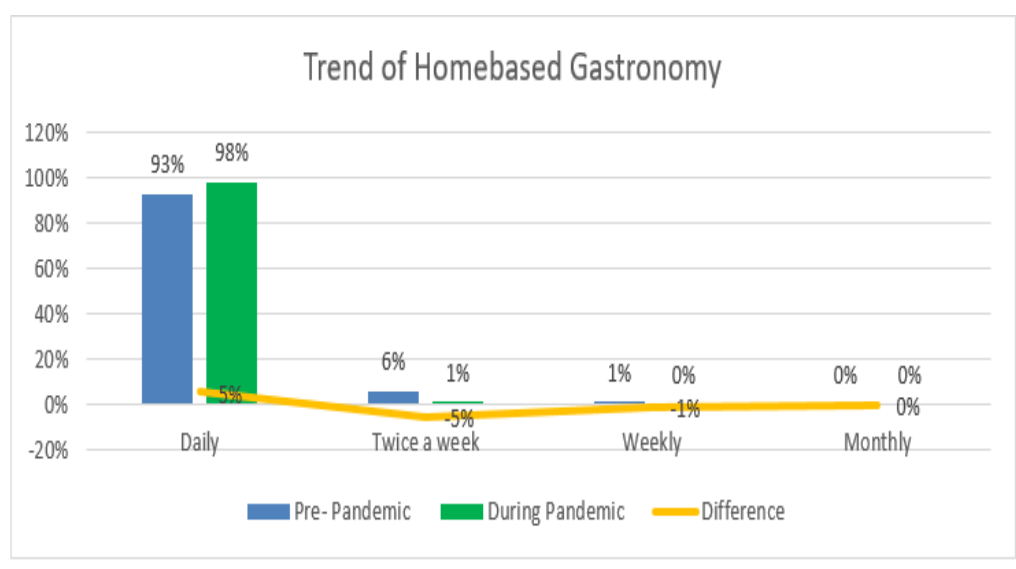

Figure1. Trend of homebased gastronomy 


\subsubsection{Increased consumption and interest in organic foods}

Figure 2 depicts a rise in the intention to eat organic food both before and after the pandemic, with a substantial increase of 31 percent. It is projected that the post-pandemic period will be $3 \%$ higher than the pandemic period. Organic food is food that is not genetically engineered and is grown without the use of chemicals such as pesticides and fertilizer [1], [22].

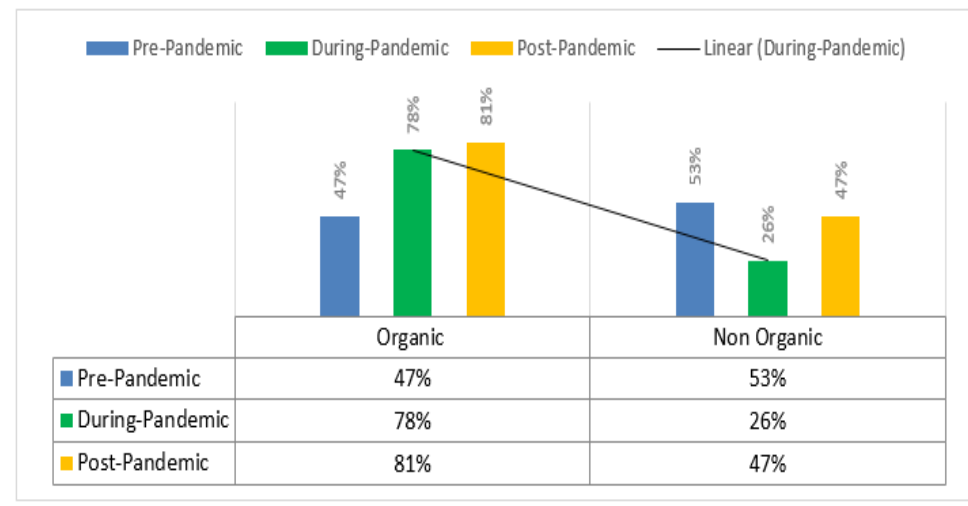

Figure 2. Consumption and interest in organic food

Figure 3 shows that the number of respondents strongly agreed that food quality and safety are important factors that have increased exponentially. The results of data analysis in the increasing awareness during the COVID 19 pandemic to forecast postpandemic are 17\%. It reflects the respondent's perception that quality of food and safety are crucial elements of food choice. Understanding of the essence that food quality and safety are critical factors in food selection.

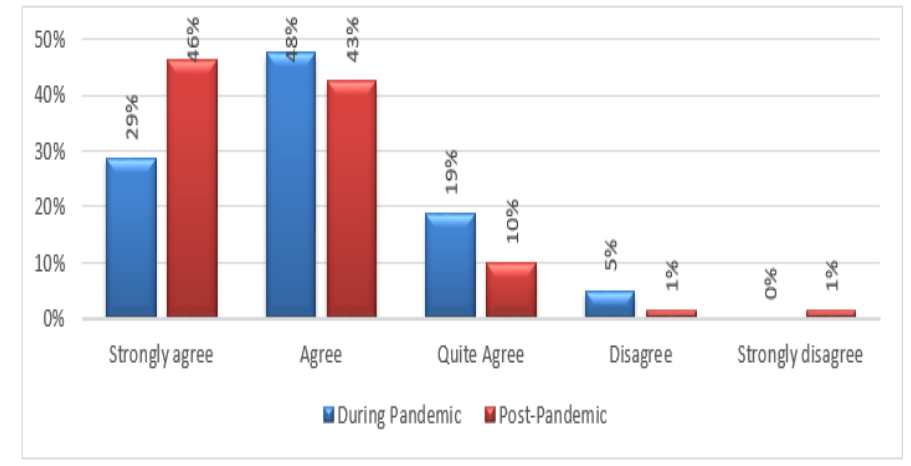

Figure 3. Food quality awareness and safety

COVID-19 pandemic has significantly changed consumer consumption habits making healthier options for Filipinos. The lockdown enabled more opportunity to develop and explore food in terms of both recipes and human relationships. Ergo, some people have reported an increase in anxiety, general inactivity, and a desire for new food stimuli [4]. We know that as of the moment, no foods or natural remedies will prevent COVID-19 infections [23]; nevertheless, healthy diet can be useful in improving immune systems and contrasting inflammatory and oxidative stress [24].

Females are more affected than males [24]. They added that those couples without children, uneducated, single individuals, children and adolescents show high levels of stress, anxiety, depression as well as psychological effect [25]-[27]. The trend in in home cooking is increasing because consumers have become more aware of the importance of cleanliness and sanitation.

This study also revealed that there is a growing awareness that food safety, health and quality are important aspects of food selection which implies that the pandemic brought change to what and how people consume food. The pandemic also led people shift from unhealthy or healthy to a healthier diet. 
This research has a realistic impact of promoting awareness to the food industry to respond to the COVID-19 pandemic conditions. Community observance is influenced by public knowledge and attitudes toward COVID-19 [28]. If every person had enough knowledge of COVID-19, the fight against this invisible enemy was soon over [29]. Through the results, an effective health policy for managing waste facilities and implementing sanitation practices in order to reduce the spread of COVID-19 is of great importance [30].

\section{CONCLUSION}

Research results provided a quantitative overview of how Filipino consumers shifted their food consumption habits before and during pandemic and the possibility of changing such after COVID-19. The pandemic taught Filipinos to eat healthier foods and go into home cooking. People have become more aware of food safety, health and quality of consuming foods. Thus, this study has theoretical and practical implications that which can lead to the improvement of our understanding of consumer consumption habits in times of pandemic. Research results can be used as a basis in offering products that can help boost immune system or can make available foods more nutritious to prevent the spread of the disease. Restaurants and any other establishments offering food for sale can also adjust to customers demand by providing healthy foods like organic products, fresh veggies and fruits to adapt to the changing consumer consumption patterns.

This study has limits on statistical analysis dominated by descriptive data on changing consumer consumption habits before, during and after the pandemic. Combined with qualitative studies, this study will provide a wider and more detailed overview of shifts in consumer habits. Further investigations should also explore the impact on consumption habits of health, society and the psychology. The results of the study also showed a greater interest in organic food among respondents. Therefore, future studies will also further investigate consumer motivation in relation to organic food consumption during a pandemic.

\section{ACKNOWLEDGMENT}

We are grateful to Quirino State University for the continuous support and guidance in all our research endeavors. This study could not have been realized without the help of the University Research and Development. Due thanks are also accorded to the respondents of this study.

\section{REFERENCES}

[1] S. S. Wachyuni and K. Wiweka, "The Changes in Food Consumption Behavior: Rapid Observational study of COVID-19 Pandemic," International Journal of Management, Innovation and Entrepreneurial Research, vol. 6, no. 2, pp. 77-87, 2020, doi: 10.18510/ijmier.2020.628.

[2] N. Liu, et al., "Prevalence and predictors of PTSS during COVID-19 outbreak in China hardest-hit areas: Gender differences matter," Psychiatry Research, vol. 287, pp. 1-7, 2020, doi: 10.1016/j.psychres.2020.112921.

[3] S. Brooks et al., "The psychological impact of quarantine and how to reduce it: Rapid review of the evidence," Lancet, vol. 395, pp. 912-920, 2020, doi: 10.1016/S0140-6736(20)30460-8.

[4] R. K. Mohapatra et al., "The recent challenges of highly contagious COVID-19, causing respiratory infections: Symptoms, diagnosis, transmission, possible vaccines, animal models, and immunotherapy," Chemical Biology and Drug Design, vol. 96, no. 12, pp. 1187-1208, 2020, doi: 10.1111/cbdd.13761.

[5] M. Yuan, J. L. Seale Jr, T. I. Wahl, and J. Bai, "The changing dietary patterns and health issues in China," China Agricultural Economic Review, vol. 11, no. 1, pp. 143-159, 2018, doi: 10.1108/CAER-12-2017-0254.

[6] L. Di Renzo et al., "Psychological aspects and eating habits during covid-19 home confinement: Results of ehlccovid-19 Italian online survey," Nutrients, vol. 12, no. 7, p. 2152, 2020, doi: 10.3390/nu12072152.

[7] M. L. Tee et al., "Psychological impact of COVID-19 pandemic in the Philippines," Journal of Affective Disorders, vol. 277, pp. 379-391, 2020, doi: 10.1016/j.jad.2020.08.043.

[8] D. V. Aguila, G. M. Gironella, and M. V. Capanzana, "Food intake, nutritional and health status of Filipino adults according to occupations based on the $8^{\text {th }}$ National Nutrion Survey 2013," Malaysian Journal of Nutrition, vol. 24, no. 3, pp. 333-348, 2018.

[9] Ebadi L, Rakhshanderou S, and Ghaffari M, "Determinants of Fast Food Consumption among Students of Tehran: Application of Planned Behavior Theory," International Journal of Pediatrics-Mashhad, vol. 6, no. 10, pp. 83078316, 2018, doi: 10.22038/ijp.2018.30329.2668.

[10] Su, X. "You Are What You Eat!" Science Translational Medicine, vol. 12, no. 534, 2020, doi: 10.1126/scitranslmed.abb2771.

[11] G. Sogari, C. V. Argumedo, M. I. Gomez, and C. Mora, "College students and eating habits: A study using an ecological model for healthy behavior," Nutrients, vol. 10, no. 12, pp. 1-16, 2018, doi: 10.3390/nu10121823.

[12] O. T. Vallejo, "Millennials' Health Related Practices Related Food Habits and Preferences," International Journal of Scientific and Research Publications (IJSRP), vol. 8, no. 9, pp. 6-11, 2018, doi: 10.29322/IJSRP.8.9.2018.p8103. 
[13] L. B. Chakraborty, M. Sahakian, U. Rani, M. Shenoy, and S. Erkman, "Urban Food Consumption in Metro Manila: Interdisciplinary Approaches towards Apprehending Practices, Patterns, and Impacts," Journal of Industrial Ecology, vol 20, no. 3, pp. 559-570. 2016, doi: 10.1111/jiec.12402.

[14] M. Loxton, R. Truskett, B. Scarf, and L. Sindone, "Consumer Behaviour during Crises: Preliminary Research on How Coronavirus Has Manifested Consumer Panic Buying, Herd Mentality, Changing Discretionary Spending and the Role of the Media in Influencing Behaviour," Journal of Risk and Financial Management, vol. 13, no. 8, pp. 121, 2020, doi: 10.3390/jrfm13080166.

[15] Armstrong G., Adam S., Denize S., and Kotler P., "Principles of marketing," Pearson Australia, pp. 136-168, 2014

[16] J. Kvintova and S. Cakirpaloglu, "Self-Esteem, Social Network Use and Life Satisfaction among College Students of Generation Xy and Z," ICERI2019 Proceedings, 2019, vol. 1, pp. 5527-5532, doi: 10.21125/iceri.2019.1324.

[17] W. Cao et al., "The psychological impact of the COVID-19 epidemic on college students in China," Psychiatry Research, vol. 287, pp. 1-5, 2020, doi: 10.1016/j.psychres.2020.112934.

[18] F. Scarmozzino and F. Visioli, "COVID-19 and the Subsequent Lockdown Modified Dietary Habits of Almost Half the Population in an Italian Sample," Foods, vol. 9, no. 5, pp. 1-8, 2020, doi: 10.3390/foods9050675.

[19] A. Ammar et al., "Effects of COVID-19 Home Confinement on Eating Behaviour and Physical Activity: Results of the ECLB-COVID19 International Online Survey," Nutrients, vol. 12, no. 6, pp. 1-13, 2020, doi: 10.3390/nu12061583.

[20] R. Muniady, A. Al Mamun, P. Y. Permarupan, and N. R. B. Zainol, "Factors influencing consumer behavior: A study among university students in Malaysia," Asian Social Science, vol. 10, no. 9, pp. 18-25, 2014, doi: 10.5539/ass.v10n9p18.

[21] S. Schoenberg et al., "Development of the home cooking environment and equipment inventory observation form (Home-cookeri $^{\mathrm{TM}}$ ): An assessment of content validity, face validity, and inter-rater agreement," Nutrients, vol. 12, no. 6, pp. 1-21, doi: 10.3390/nu12061853.

[22] Mei-Fang Chen, "Consumer attitudes and purchase intentions in relation to organic foods in Taiwan: Moderating effects of food-related personality traits," Food quality and preference, vol. 18, no. 7, pp. 1008-1021, 2007, doi: 10.1016/j.foodqual.2007.04.004.

[23] U. Halbreich and L. S. Khan, "Atypical depression, somatic depression and anxious depression in women: Are they gender-preferred phenotypes?," Journal of Affective Disorders, vol. 102, no. 1-3, pp. 245-58, 2007, doi: 10.1016/j.jad.2006.09.023.

[24] Off-Label Use of Medicines for COVID-19. WHO. 2020. [Online]. Available: https://www.who.int/news-room/ commentaries/detail/off-label-use-of-medicines-for-covid-19

[25] M. Tee, et al., "Psychological impact of COVID-19 pandemic in the Philippines," Journal of Affective Disorders, vol. 277, pp. 379-391, 2020, doi: 10.1016/j.jad.2020.08.043.

[26] W. Cullen, G. Gulati, and B. D. Kelly, "Mental health in the COVID-19 pandemic," QJM: An International Journal of Medicine, vol. 113, no. 5, pp. 311-312, 2020, doi: 10.1093/qjmed/hcaa110.

[27] Y. Wang, Y. Wang, Y. Chen, and Q. Qin, "Unique epidemiological and clinical features of the emerging 2019 novel coronavirus pneumonia (COVID-19) implicate special control measures," Journal of Medical Virology, vol. 92, no. 6, pp. 568-576, 2020, doi: 10.1002/jmv.25748.

[28] N. A. Pascawati and T. B. T. Satoto, "Public knowledge, attitudes and practices towards COVID-19," International Journal of Public Health Science (IJPHS), vol. 9, no. 4, pp. 292-302, 2020, doi: 10.11591/ijphs.v9i4.20539.

[29] Jomell Santiago and R. L. Cajucom, "Knowledge about covid-19 among university students before the implementation of the enhanced community quarantine in Philippines," International Journal of Public Health Science (IJPHS), vol. 9, no. 4, pp. 321-328, 2020, doi: 10.11591/ijphs.v9i4.20545.

[30] Hassan Hussein Musa, "COVID-19 outbreak and medical waste: Challenge in hand," International Journal of Public Health Science (IJPHS), vol. 9, no. 3, pp. 153-154, 2020, doi: 10.11591/ijphs.v9i3.20523. 